\title{
Relationship between primary caregivers' knowledge of schizophrenia and stigma faced by persons with schizophrenia
}

\author{
Dhritishree Das ${ }^{1}$, Satabdi Chakraborti², Ram Pratap Beniwal ,", Ankur Sachdev ${ }^{4}$ \\ ${ }^{\mathbf{1}}$ Psychiatric Social Worker, ${ }^{\mathbf{A}}$ Associate Professor and Head, ${ }^{\mathbf{3} 4}$ Assistant Professor, ${ }^{\mathbf{1 , 2}}$ Dept. of Psychiatric Social Work, ${ }^{\mathbf{3}, \mathbf{4}}$ Dept. of \\ Psychiatry, ${ }^{1-3}$ Centre of Excellence in Mental Health, PGIMER- Dr. Ram Manohar Lohia Hospital, New Delhi, ${ }^{4}$ ESIC Medical College and \\ Hospital, Faridabad, Haryana, India \\ *Corresponding Author: Ram Pratap Beniwal \\ Email: beniwal_9@yahoo.co.in
}

\begin{abstract}
Introduction: Studies have found greater experiences of stigma among persons with schizophrenia than other mental disorders. Caregiver's knowledge and perception of schizophrenia might affect the perceived stigma by the patients. However, this relationship between knowledge of schizophrenia among caregivers and stigma faced by the persons with schizophrenia has not been explored.

Aim and Objective: To assess the relationship between caregivers' knowledge of schizophrenia and the stigma faced by the persons with schizophrenia.

Materials and Methods: A cross-sectional observational study was conducted on 70 persons with schizophrenia of minimum one-year duration and living with their primary caregivers' for at least 6-months. Subjects of both genders with age range of 18 to 60 years were assessed with 'internalized stigma of mental illness' (ISMI) scale and 'knowledge about schizophrenia interview' (KASI) scale, along with their primary caregivers.

Results: We found a negative co-relation between primary caregivers' knowledge and the stigma faced by the persons with schizophrenia. Caregivers knowledge about 'etiology' $(\mathrm{p}=0.01)$, 'course \& prognosis' $(\mathrm{p}=0.03)$ and overall knowledge about 'schizophrenia' $(\mathrm{p}=0.03)$ was significantly associated with reduced 'perceived discrimination' faced by the persons with schizophrenia.

Conclusion: The study concludes that primary caregivers' awareness and knowledge about different aspects of schizophrenia shows significant negative correlation with perceived discrimination among persons with schizophrenia. However, knowledge assessed was based on the biomedical model. Therefore, development of assessment tools for knowledge about schizophrenia based on culture specific beliefs is highly recommended.
\end{abstract}

Keywords: Primary caregiver, Stigma, Knowledge, Schizophrenia.

\section{Introduction}

Stigma is a Greek word meaning 'mark' originally used to brand criminals in order to identify publicly, which was later used to refer to the sense of collective disapproval and a group of negative perceptions attached to particular people, trait, and condition. Overall, the process of stigmatization identifies and discriminates against the group whose characteristics are kept under question. ${ }^{1}$ Stigma is nothing but a label that is a product of negative perception, poor understanding and overgeneralization of these labels. ${ }^{2}$ However, new researchers have conceptualized stigma into three subtypes: (a) Internalized Stigma (b) Interpersonal Stigma (c) Institutional Stigma. ${ }^{3}$

Study of symptoms and course of schizophrenia has found that initial perception of symbolic threat of the person with active psychopathology results in labeling with deviant characteristics and ultimately involving in consensual social sharing through practicing discrimination against the persons with the disorder. ${ }^{4}$ Stigmatizing attitudes are significantly more towards people with mental illness than people with physical disability. ${ }^{5}$

Studies from South India have found that family members of persons living with schizophrenia were often concerned for other family members for not being able to marry, experiencing avoidance by friends, relatives or neighbors. ${ }^{6,7}$ However, the experience of stigma is not limited to the social context. Persons with schizophrenia have faced hostility and stigmatizing reactions from family members also. ${ }^{8}$ Lack of knowledge about mental illness has been described as one of the components of the stigma construct itself. ${ }^{9,10}$ Therefore, better understanding of this relationship may help to reduce the impact of stigma. ${ }^{11}$ Lack of knowledge regarding nature of illness and behavioral symptoms results in higher stigma and discriminatory practices towards people with mental illness especially with schizophrenia. ${ }^{12}$ In India, persons living with schizophrenia bear significant social disapproval in terms of marriage and have experienced internalized forms of stigma like sense of alienation more than negative discrimination. ${ }^{13}$ While caregivers' having better knowledge about schizophrenia in terms of biomedical illness model did not reduce stigma. ${ }^{14,15}$ A recent study conducted by Pingali et al, found that significant number of females and involuntarily admitted patients irrespective of their diagnosis experienced internalized stigma. ${ }^{16}$

Stigma and discrimination have been suggested to be the common barriers while accessing treatment and thus resulting in delay in psychiatric treatment. Schizophrenia is a chronic psychiatric illness with a variable course, fraught with stigma and outcomes that are determined by social support and family factors. ${ }^{17}$ Another recent study conducted in India found that 80 percent of person with mental disorder did not seek treatment despite being ill for more than 12 months due to the associated stigma. ${ }^{18}$ 


\section{Aims and Objectives}

The knowledge regarding schizophrenia among primary caregivers in relation to the stigma faced by the persons with schizophrenia in family context has not been studied much. The study aims to assess the relationship between caregivers' knowledge of schizophrenia and the stigma faced by the persons with schizophrenia.

\section{Materials and Methods}

We conducted a cross sectional observational study including 70 persons with schizophrenia diagnosed by a psychiatrist with minimum one year of illness, who were living with their primary caregivers' for at least 6 months. Both genders between 18 to 60 years of age were included in study. Primary caregivers who were living with the person with schizophrenia and providing continuous care for last 6 months were included. The study was conducted in outpatient department (OPD) of Department of Psychiatry of a tertiary care hospital in New Delhi. Patients approaching the psychiatry OPD from May 2018 to June 2018 and willing to participate were referred by the treating psychiatrist to the researcher. Consenting participants were screened based on Diagnostic and Statistical Manual (DSM-5) checklist. Persons with schizophrenia along with their primary caregivers having any co-morbid illness such as neurological, mental retardation and substance dependence except nicotine were excluded from the study.

Simple random sampling technique has been used for the study and sample size was calculated using G-Power analysis using Power (1- $\beta$ err prob) at $=0.80$, where calculated sample size came out to be 64 but keeping in mind chances of attrition, sample size of 70 was kept for this study. The sample size calculation was based on the study by Koschorke et al. (2017). ${ }^{14}$ Study approval and ethical permission was taken from the Institutional review board and the Institutional ethics committee of hospital respectively.

\section{Scales used}

DSM-5 criteria checklist: ${ }^{19}$ This checklist consisted of DSM-5 criteria for re-confirming the diagnosis of schizophrenia before recruitment into the study.

\section{Socio-demographic Data Sheet}

Internalized Stigma of Mental Illness (ISMI) Scale: Hindi version (Singh et al., 2016) was used to assess internalized stigma from the perspective of stigmatized individuals on person with schizophrenia. ${ }^{20}$ It is an interview-based instrument comprises of 29 questions divided into 5 sectionsalienation, stereotype endorsement, perceived discrimination, social withdrawal and stigma resistance rated against 4 points- strongly disagree, disagree, agree and strongly agree. Originator of the scale (Ritsher et al, 2003; Ritsher \& Phelan, 2004) used a cut off of 2.5 for total \& subscales of ISMIS to categorize the presence or absence of stigma. ${ }^{21,22}$ In this study, we used original cut-offs. Hindi version of ISMI Scale was found to have a good internal consistency (Cronbach's alpha was 0.863), split- half reliability (Spearman- Brown coefficient- 0.661; Guttmann's split- half coefficient- 0.645 ), test-retest reliability and cross- language equivalence for all the items and convergent validity in the form of significant correlations with EMIC Stigma Scale.

Knowledge about Schizophrenia Interview (KASI) scale (Barrowclough et al., 1987): This scale was used with the primary caregiver and was designed to assess/evaluate knowledge, beliefs and attitudes about 6 broad aspects of schizophrenia (Diagnosis, Symptomatology, Etiology, Medication, Course \& Prognosis and Management) and the effects of that information on family member's behavior. ${ }^{23}$ The scale has 27 items across 6 sections. Each section is scored on a 4-point scale, 1-4. A score of 1 equals a negative value in that the family member gives information which if acted upon may be detrimental to the client. A score of 2 equals a neutral value in that the family member knows little relevant information but gives no information that if acted upon may be detrimental to the client. A score of 3 equals positive value in that the family member gives information which if acted upon may be beneficial to the client. A score of 4 equals positive value in that in addition to information provided for a score of 3 , the family member has shown a wider knowledge and understanding of the assessed aspect of schizophrenia.

The KASI scale has acceptable psychometric properties including reliability, validity and treatment sensitivity (Barrowclough \& Tarrier, 1987). ${ }^{23}$ This scale was translated from English to Hindi and Hindi to English by four different translators who had no knowledge of this scale prior to translation. Thus, after a pilot administration on 5 subjects, the translated Hindi version was used in this study.

\section{Statistical Analysis}

All the data computation was done using the SPSS 20 (statistical package for the social sciences). ${ }^{(24)}$ Under the descriptive statistics- frequency, percentages of categorical variables (socio-demographic variables such as gender, marital status, education, employment, types of family structure etc.) were computed. For continuous variables such as age of persons with schizophrenia, age of primary caregivers and total duration of illness of persons with schizophrenia were computed in terms of mean and standard deviation.

Spearman rank correlation was used to correlate the ISMI scale components and KASI scale components, ISMI scale components and KASI scale components with age of persons with schizophrenia and their total duration of illness. Analysis of variances (ANOVA) was computed for comparison of employment and marital status of persons with schizophrenia with ISMI scale components and primary caregivers with KASI scale components. It was also computed to compare age of onset, marital status and employment of persons with schizophrenia with ISMI scale components. Then, ANOVA was also computed to compare KASI scale components with marital status and employment of primary caregivers. 


\section{Results}

Out of 70 participants with schizophrenia, 58.6 percent were males and 41.4 percent were females. However, in terms of primary caregivers, 64.3 percent were males and 35.7 percent were females. Moreover, 40 percent participants with schizophrenia were unmarried, 50 percent were unemployed and 75.7 percent belonged to nuclear family structure. The mean of total duration of illness is $7.33 \pm 4.78$ with 64.3 percent having "visit to psychiatrist" as their first contact of treatment. (Table 2)

Table 1: Socio demographic and clinical variables

\begin{tabular}{|c|c|c|c|}
\hline \multicolumn{2}{|c|}{ Variables } & \multirow{3}{*}{$\begin{array}{c}\text { Persons with } \\
\text { schizophrenia }(\mathbf{N}=\mathbf{7 0}) \\
\text { Frequency }(\mathbf{\%}) \\
41(58.6) \\
\end{array}$} & \multirow{3}{*}{$\begin{array}{c}\begin{array}{c}\text { Primary } \\
\text { caregivers }(\mathbf{N}=70) \\
\text { Frequency }(\boldsymbol{\%})\end{array} \\
45(64.3) \\
\end{array}$} \\
\hline & & & \\
\hline Gender & Male & & \\
\hline & Female & $29(41.4)$ & $25(35.7)$ \\
\hline \multirow[t]{4}{*}{ Marital Status } & Single & $40(57.1)$ & $9(12.9)$ \\
\hline & Married & $19(27.1)$ & $54(77.1)$ \\
\hline & Separated/Divorced & $11(15.7)$ & $1(1.4)$ \\
\hline & Widow/Widower & 0 & $6(8.6)$ \\
\hline \multirow[t]{6}{*}{ Education } & Not Formally Educated & $5(7.1)$ & $16(22.9)$ \\
\hline & $1^{\text {st }-5^{\text {th }} \text { Class }}$ & 0 & $1(1.4)$ \\
\hline & 6th- $8^{\text {th }}$ Class & $4(5.7)$ & $5(7.1)$ \\
\hline & $9^{\text {th }}-10^{\text {th }}$ Class & $9(12.9)$ & $9(12.9)$ \\
\hline & $11^{\text {th }}-12^{\text {th }}$ Class & $29(41.4)$ & $15(21.4)$ \\
\hline & Graduate and Above & $23(32.9)$ & $24(34.3)$ \\
\hline \multirow{5}{*}{ Employment } & Never Employed & $35(50)$ & 0 \\
\hline & Employed & $19(27.1)$ & $46(65.7)$ \\
\hline & Student & $7(10)$ & $2(2.9)$ \\
\hline & Home-maker & $9(12.9)$ & $13(18.6)$ \\
\hline & Retired & 0 & $9(12.9)$ \\
\hline \multicolumn{4}{|c|}{ Common socio-demographic variable of persons with schizophrenia and their primary caregivers $(\mathrm{N}=70)$} \\
\hline \multirow[t]{2}{*}{ Types of Family Structure } & Nuclear Family & \multicolumn{2}{|c|}{$53(75.7 \%)$} \\
\hline & Joint Family & \multicolumn{2}{|c|}{$17(24.3 \%)$} \\
\hline \multicolumn{2}{|l|}{ Total duration of illness } & \multicolumn{2}{|c|}{ Mean (Range) $7.33 \pm 4.78(1-20)$} \\
\hline \multirow[t]{2}{*}{ First Contact of Treatment } & Faith Healer & \multicolumn{2}{|c|}{$25(35.7 \%)$} \\
\hline & Psychiatrist & \multicolumn{2}{|c|}{$45(64.3 \%)$} \\
\hline
\end{tabular}

Components of KASI scale was correlated with age and Total Duration of Illness, where significant positive correlation was found between medication and Total
Duration of Illness $(\mathrm{p}<0.01)$. However, no significant correlation found between ISMI scale components with age and Total Duration of Illness. (Table 2)

Table 2: Correlation of ISMI scale and KASI scale components with age and TDI

\begin{tabular}{|l|c|c|}
\hline Content & \multicolumn{2}{|c|}{ Variable } \\
\hline ISMI & Age r (p value) & TDI r (p value) \\
\hline Alienation & $-0.177(0.143)$ & $-0.079(0.516)$ \\
\hline Stereotype & $-0.152(0.209)$ & $-0.054(0.655)$ \\
\hline Perceived Discrimination & $-0.156(0.197)$ & $-0.159(0.189)$ \\
\hline Social Withdrawal & $-0.077(0.527)$ & $-0.081(0.504)$ \\
\hline Stigma Resistance & $0.068(0.578)$ & $0.083(0.496)$ \\
\hline ISMI Total & $-0.167(0.166)$ & $-0.105(0.385)$ \\
\hline KASI & Age & TDI \\
& $\mathrm{r}(\mathrm{p}$ value) & r (p value) \\
\hline Diagnosis & $0.115(0.345)$ & $0.098(0.421)$ \\
\hline Symptomatology & $0.086(0.476)$ & $0.109(0.370)$ \\
\hline Etiology & $-0.090(0.457)$ & $-0.106(0.383)$ \\
\hline Medication & $0.228(0.058)$ & $0.350(0.003) * *$ \\
\hline Course and Prognosis & $0.054(0.657)$ & $-0.055(0.650)$ \\
\hline Management & $0.004(0.977)$ & $-0.025(0.840)$ \\
\hline KASI Total & $0.052(0.667)$ & $0.044(0.716)$ \\
\hline
\end{tabular}

**Correlation significant at <0.01 level (2-tailed); ISMI: Internalized stigma of mental illness; KASI: Knowledge about schizophrenia interview; TDI: Total duration of illness 
Components of ISMI scale were correlated with KASI scale components, where significant negative correlation was found between perceived discrimination with knowledge about etiology $(\mathrm{p}<0.01)$, course \& prognosis $(\mathrm{p}<0.05)$ and overall knowledge about schizophrenia $(\mathrm{p}<0.05)$.(Table 3$)$

Table 3: Correlation of ISMI Scale components with KASI scale components

\begin{tabular}{|c|c|c|c|c|c|c|c|}
\hline Variables & $\begin{array}{l}\text { Diagnosis } \\
\mathbf{r} \text { (p value) }\end{array}$ & $\begin{array}{c}\text { Symptomatology } \\
\text { r (p value) } \\
\end{array}$ & $\begin{array}{c}\text { Etiology } \\
\text { r (p value) }\end{array}$ & $\begin{array}{l}\text { Medication } \\
\mathbf{r} \text { (p value) }\end{array}$ & $\begin{array}{c}\text { Course and } \\
\text { Prognosis } \\
\mathrm{r} \text { (p value) }\end{array}$ & $\begin{array}{c}\text { Management } \\
\mathbf{r} \text { (p value) }\end{array}$ & $\begin{array}{c}\text { KASI Total } \\
\text { Score } \\
\mathbf{r} \text { (p value) } \\
\end{array}$ \\
\hline Alienation & $0.009(0.942)$ & $-0.202(0.093)$ & $-0.197(0.103)$ & $-0.015(0.900)$ & $\begin{array}{l}-0.209 \\
(0.082) \\
\end{array}$ & $0.030(.805)$ & $\begin{array}{l}-0.203 \\
(0.092) \\
\end{array}$ \\
\hline $\begin{array}{l}\text { Stereotype } \\
\text { Endorsement }\end{array}$ & $0.059(0.627)$ & $-0.061(0.618)$ & -0.043 & $\begin{array}{l}-0.006 \\
(0.960) \\
\end{array}$ & $\begin{array}{l}-0.006 \\
(0.589) \\
\end{array}$ & 0.1 & $\begin{array}{l}-0.073 \\
(0.550) \\
\end{array}$ \\
\hline \begin{tabular}{|l|} 
Perceived \\
Discrimination \\
\end{tabular} & \begin{tabular}{|l|}
$-0.049(.687)$ \\
\end{tabular} & $\begin{array}{c}-0.088(.469) \\
\end{array}$ & $\begin{array}{c}-0.293^{* *} \\
(0.014) \\
\end{array}$ & $0.030(0.803)$ & $\begin{array}{l}-0.260^{*} \\
(0.030)\end{array}$ & $-0.103(.395)$ & $\begin{array}{l}-0.253^{*} \\
(0.034) \\
\end{array}$ \\
\hline \begin{tabular}{|l|} 
Social \\
Withdrawal \\
\end{tabular} & $0.009(0.938)$ & $-0.160(0.185)$ & $-0.221(0.066)$ & $\begin{array}{c}0.077 \\
(0.529) \\
\end{array}$ & $\begin{array}{l}-0.124 \\
(0.305) \\
\end{array}$ & $0.064(0.597)$ & $\begin{array}{l}-0.157 \\
(0.193) \\
\end{array}$ \\
\hline \begin{tabular}{|l|} 
Stigma \\
Resistance \\
\end{tabular} & $0.097(0.424)$ & $-0.028(0.817)$ & $0.112(0.357)$ & $\begin{array}{c}0.158 \\
(0.193) \\
\end{array}$ & $\begin{array}{c}0.122 \\
(0.313) \\
\end{array}$ & $0.003(0.977)$ & $\begin{array}{c}0.084 \\
(0.488) \\
\end{array}$ \\
\hline $\begin{array}{l}\text { ISMI Total } \\
\text { Score }\end{array}$ & $0.052(0.667)$ & $-0.144(0.233)$ & $-0.182(0.132)$ & $0.050(0.682)$ & $\begin{array}{l}-0.153 \\
(0.206) \\
\end{array}$ & $0.035(0.773)$ & $\begin{array}{l}-0.169 \\
(0.163) \\
\end{array}$ \\
\hline
\end{tabular}

** Correlation is significant at $<0.01$ level (2-tailed); ${ }^{*}$ Correlation is significant at $<0.05$ level (2-tailed).

Age of onset, ISMI components were separately compared with marital status of persons with schizophrenia, where significant differences was found $(p<0.01)$ in terms of age of onset, significant difference found $(p<0.05)$ in terms of perceived discrimination. ISMI components were also compared with employment status of persons with schizophrenia, where significant difference $(\mathrm{p}<0.01)$ in terms of stigma resistance.

KASI components were compared with their marital status and employment status, where significant difference was found $(\mathrm{p}<0.01)$ in terms of medication. (Table 4)

Table 4: Comparison of means values of various variables with ISMI and KASI components

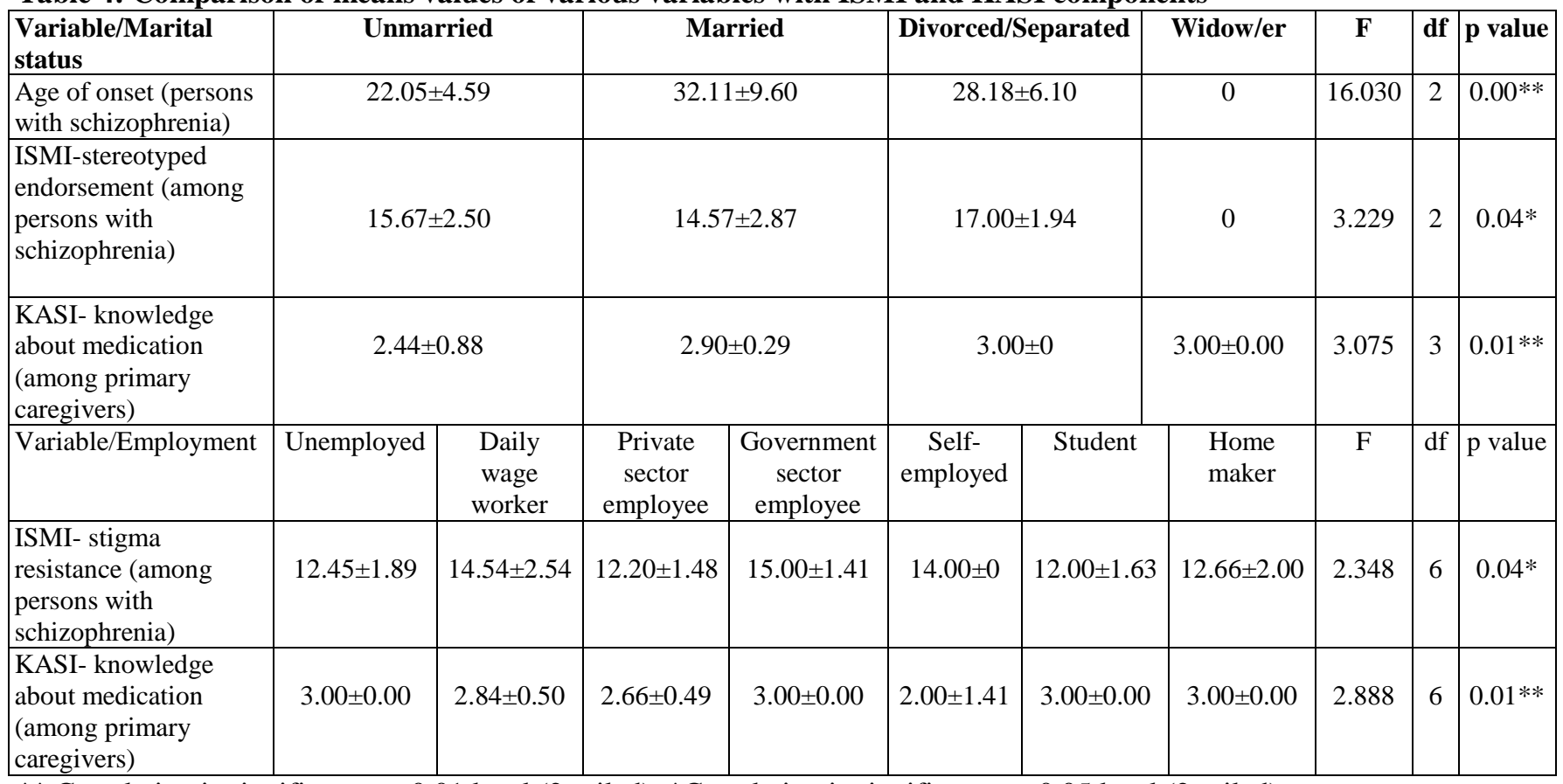

** Correlation is significant at $<0.01$ level (2-tailed); ${ }^{*}$ Correlation is significant at $<0.05$ level (2-tailed)

\section{Discussion}

The relationship between primary caregivers' knowledge and stigma faced by the persons with schizophrenia was planned to be investigated in this study. Caregivers knowledge about 'etiology' $(p=0.01)$, 'course \& prognosis' $(\mathrm{p}=0.03)$ and overall knowledge about 'schizophrenia' $(\mathrm{p}=0.03)$ was significantly associated with reduced 'perceived discrimination' faced by the persons with schizophrenia. 
We found that among the primary caregivers', 64.3 percent were males and 35.7 percent were females, suggesting higher number of male caregivers. This is contradictory to previous review findings of 42 studies done by Caqueo et al., (2014), where majority of the caregivers were females (mothers). ${ }^{25}$ Another study contradicting this finding is by Awad et al., (2008) where females either sisters, wives or mothers were the primary caregivers' of persons with schizophrenia. ${ }^{26}$ This difference may be due to responsibility allocation of primary caregivers based on 'gender' in the family that can be kept for further study directions as no such study supporting this proposition.

When primary caregiver's knowledge about schizophrenia was aimed to assess any association with age and total duration of illness of persons with schizophrenia, positive correlation was found between caregivers' knowledge about medication and total duration of illness at a significant level of $(\mathrm{p}=<0.01)$ (shown in table 1$)$, to which no supporting studies could be found. However, in a study by Koschorke et al. (2017), where they measured only the caregivers' knowledge about schizophrenia found higher knowledge about management than medication, diagnosis, to the least knowledge about course \& prognosis. ${ }^{14}$

As per our study's principle aim, we found a negative correlation of 'perceived discrimination' with the primary caregivers' knowledge about 'etiology' $(\mathrm{p}=0.01)$ and 'course $\&$ prognosis' $(p=0.03)$ and 'total KASI score' $(p=0.03)$, shown in table 3 , indicating higher perceived discrimination with lower knowledge about 'etiology' and 'course \& prognosis' and with overall lower knowledge about schizophrenia, or vice-versa. Contrary to this, study finding by Koschorke et al. (2014), where caregivers were found practicing discrimination against persons with schizophrenia despite of having higher level of knowledge about schizophrenia. ${ }^{13}$ Suggesting knowledge about schizophrenia in terms of biomedical model may increase stigma which was supported by findings of Schomerus et al., (2014) where they suggested biological causal explanation to be lesser beneficial for persons with schizophrenia than alcohol dependence. ${ }^{27}$ Even, Yang et al., (2012), found biogenetic causal explanation such as "chemical imbalance, brain disease" associated with greater desire for social distance from persons with schizophrenia. ${ }^{28}$ Therefore, the proposition put forth by Charles et al., (2007) and Das et al., (2006) to consider context specific beliefs of primary caregivers' while providing psycho-educational interventions may be researched as more than a decade has passed for this proposition provided by them..$^{29,30}$

While comparing type of employment among persons with schizophrenia experiencing internalized stigma, had significant difference in 'stigma-resistance' $(\mathrm{p}=<0.05)$ (shown in table 4) i.e. the government employment group were highest in resisting stigma $(15.00 \pm 1.41)$ which was least resisted by student group $(12.00 \pm 1.63)$. This has been supported by a study of Grambal et al., (2016), where significant difference was found among employment groups in the 'stereotype endorsement' and 'social withdrawal' components of internalized stigma. ${ }^{31}$ However, finding by
Grover et al., (2016) contradicted the present finding as no significant difference was found, but he found overall lower level of functioning. ${ }^{15}$

The comparison of marital status of persons with schizophrenia, with internalized stigma was analyzed with the aim to explore if any difference exist between persons either unmarried, married or separated, found significant difference with 'stereotyped endorsement' at $<0.05$ level (shown in table 4) with the highest stereotyped endorsement among separated persons $(17.00 \pm 1.94)$ to least among married $(14.57 \pm 2.87)$ persons with schizophrenia which has been contradicted with study finding by Grambal et al., (2016), where no significant difference was found among the marital group with ISMI scale components. ${ }^{31}$

Marital status and employment status of primary caregivers' in terms of KASI scale components, if any differences exits analyzed, found significant differences among both these groups at significance level at 0.01 (shown in table 4), where in terms of 'knowledge about medication' having higher knowledge among the widow/er caregivers' $(3.00 \pm 0.00)$ to least knowledge among unmarried caregivers' $(2.44 \pm 0.88)$, whereas among employment status, the highest knowledge about medication was among home-maker, retired, self-employed and daily wage worker $(3.00 \pm 0.00)$ with the least knowledge among students $(2.00 \pm 1.41)$. However, no similar findings are present in previous literature but in a study by Koschorke et al., (2017) as mentioned above has found knowledge about 'management' to be the highest with the least knowledge about 'course \& prognosis'. ${ }^{14}$

Lastly, as the primary aim of our present study has included the family context, therefore any difference between type of family structure in terms of knowledge about schizophrenia among the primary caregivers was explored, where significant difference was found in terms of knowledge about medication at significant level $(p=<0.05)$ indicating higher knowledge among nuclear family $(2.92 \pm 0.27)$ than joint family $(2.65 \pm 0.70)$. It may be due to that 75.7 percent of participants belonged to nuclear family and only 24.3 percent belongs to joint family. No similar findings are present in this regard. However, Grover et al., (2016) assessed the ISMI scale components with the type of family structure, and found no significant difference contrary to our present finding. ${ }^{15}$

\section{Conclusion}

In this study, knowledge about etiology, course, prognosis and overall knowledge about schizophrenia has shown significant negative correlation with perceived discrimination among the persons with schizophrenia. Overall, primary caregivers' knowledge regarding schizophrenia is crucial but in this study the knowledge assessed was based on biomedical model. Therefore, development of assessment tool for knowledge about schizophrenia based on culturally specific beliefs is highly recommended. 


\section{Limitations and Future Direction}

Our study has sample that includes person with schizophrenia along with their one of the primary caregivers presented at the out-patient department of the tertiary care hospital so these findings could not be generalized. Selection bias and recall bias cannot be ruled out. Sample size was relatively small. Owing to limited numbers of primary caregivers', gender and family allocated responsibility in terms of care giving could not be studied.

Establishment of a formal psycho-education module that can enhance primary caregivers' knowledge about schizophrenia against the context specific belief of the caregivers, could be further studied with an outcome in reduced caregivers' discrimination towards persons with schizophrenia. Further research can also be focused upon establishment of a module aiming to develop 'stigma resistance' along with positive coping for overall improved social functioning among persons with schizophrenia.

\section{Acknowledgment: Nil.}

\section{Conflicts of Interest: Nil.}

\section{References}

1. Goffman, E. (1963). Stigma: notes on the management of spoiled identity. Englewood Cliffs, N.J: Prentice-Hall.

2. Scheff, T. J. (1967). Mental Illness and Social Processes. New York: Harper \& Row Publishers.

3. Hatzenbuehler, M.L., Link, B.G. (2014). Introduction to the special issue on structural stigma and health. Social Science \& Medicine (1981), 103, 1-6.

4. Stangor, C., Crandall, C.S. (2000). Threat and the social construction of stigma. In: Heatherton TF, Kleck RE, Hebl MR, Hull JG, editors. The social psychology of stigma. New York: Guilford Press. p73.

5. Corrigan, P.W., Watson, A.C. Understanding the impact of stigma on people with mental illness. World Psychiatry, 2002;1(1):16-20.

6. Raguram R., Raghu T.M., Vounatsou P., Weiss M.G. (2004). Schizophrenia and the cultural epidemiology of stigma in Bangalore, India. J Nerv Ment Dis. 2004;192(11):734-744.

7. Thara R., Kamath S., Kumar S. Women with schizophrenia and broken marriages-doubly disadvantaged? part I: patient perspective. International Journal Social Psychiatry, 2003;49(3):225-232.

8. Murthy, R.S., (2005). Stigma of mental illness in the Third World. In: Okasha, A., Stefanis, C.N. (Eds). Perspectives on the Stigma of Mental Illness. World Psychiatric Association, Cairo.

9. Thornicroft, G., (2006). Shunned: Discrimination against People with Mental Illness. Oxford University Press, Oxford.

10. Jorm AF, Barney LJ, Christensen H, Highet NJ, Kelly CM, Kitchener BA., (2006). Research on mental health literacy: what we know and what we still need to know. Aust New Zealand J Psychiatry.

11. Clement S., Jarrett M., Henderson C., Thornicroft G., (2010). Messages to use in population-level campaigns to reduce mental health-related stigma: consensus development study. Epidemiol Psichiatr Soc.

12. Shrivastava A, Johnston ME, Thakar M, Shrivastava S, Sarkhel G, Sunita I, Parkar S., (2011). Impact and origin of stigma and discrimination in schizophrenia: Patient perceptions. Stigma Research and Action.
13. Koschorke M, Padmavati R, Kumar S, Cohen A, Weiss HA, Chatterjee S., (2014). Experiences of stigma and discrimination of people with schizophrenia in India. Soc Sci Med.

14. Koschorke M, Padmavati R, Kumar S, Cohen A, Weiss H.A, Chatterjee S, Varghese M, Patel V, Thornicroft G, John S, Pereira J., (2017). Experiences of stigma and discrimination faced by family caregivers of people with schizophrenia in India. Soc Sci Med.

15. Grover S, Singh A, Mattoo S.K.., (2016). Stigma and its correlates in patients with schizophrenia attending a general hospital psychiatric unit. Indian J Psychiatry. 2016;58(3):291300.

16. Pingali S, Rao S.S, Umashankar M., (2018). A Comparative study of internalized stigma and its correlates among different psychiatric disorders in remission. Telegana J Psychiatry, 2018;4(1):29-33.

17. Walker EF., (2013). Schizophrenia: A Life-Course Developmental Perspective. New York: Academic Press.

18. Afshan Y., (2016, October 23). India needs to talk about mental illness. The Hindu.

19. American Psychiatric Association. (2013). Diagnostic and statistical manual of mental disorders (Fifth edition). Arlington, VA: American Psychiatric Publishing.

20. Singh A., Grover S., Mattoo S.K., (2016). Validation of Hindi version of internalized stigma of mental illness scale. Indian $J$ Soc Psychiatry. 2016;32:104-114.

21. Ritsher JB, Otilingam PG, Grajales M. Internalized stigma of mental illness: Psychometric properties of a new measure. Psychiatric Res. 2003;121:31-49.

22. Ritsher JB, Phelan JC. Internalized stigma predicts erosion of morale among psychiatric outpatients. Psychiatry Res. 2004;129:257-265.

23. Barrowclough C., Tarrier N., Watts S., Vaughn C., Bamrah J.S., Freeman H.L., (1987). Assessing the functional value of relatives' knowledge about schizophrenia: A preliminary report. Br J Psychiatry. 1-8.

24. IBM Corp. BM SPSS Statistics for Windows, Version 20.0. Armonk, NY: IBM Corp.; Released 2011.

25. Caqueo AU, Miranda C, Perez R, Tapia M. An updated review on burden on caregivers of schizophrenia patients. Psicothema.

26. Awad AG, Voruganti LN. The burden of schizophrenia on caregivers: a review. Pharmacoeconomics.2008;26:149-162.

27. Schomerus G, Matschinger H, Angermeyer MC.(2014). Causal beliefs of persons with mental illness: A Comparative analysis of schizophrenia, depression, alcohol dependence. Psychological Medicine.

28. Yang LH, Wonpat AJ. Causal beliefs and effects upon mental illness identification among Chinese immigrant relatives of individuals with psychosis. Community Mental Health J. 2012;48(4):471-476.

29. Charles H, Manoranjitham S, Jacob K., (2007). Stigma and Explanatory models among people with Schizophrenia and their relatives in Vellore, South India. Int J Social Psychiatry. 2007;53(4):325-332.

30. Das S, Saravanan B, Karunakaran KP, Manoranjitham S, Ezhilarasu P, Jacob KS. Effect of a structured educational intervention on explanatory models of relatives of patients with Schizophrenia: Randomized Controlled Trial. Br J Psychiatry. 2006;188:286-287.

31. Grambal A, Latalova K, Prasko J, Holubova M, Ociskova M, Vrbova K, Kamaradova D, Slepecky M, Zartkova M., (2016). Self-stigma and schizophrenia: a cross-sectional study. Neuropsychiatric Disease and Treatment, 2016;12:3011-3020. 